\title{
Self-management following a cardiac event in people of Chinese ethnicity living in Western countries: a scoping review
}

\section{INTRODUCTION}

Cardiovascular disease is a major cause of deaths and disability worldwide [1]. People who experience a cardiac event such as acute coronary syndrome (ACS) including unstable angina, as well as ST-elevation and non-STelevation myocardial infarction (STEMI and non-STEMI), often require urgent interventions that include hospital admission and related procedures such as coronary artery bypass graft (CABG) and percutaneous coronary intervention $(\mathrm{PCl})$. ACS is often associated with physical and psychological sequelae including ongoing disease symptoms, reduced physical function, limitation in daily activities [2, 3], and depression or anxiety [4-6]. These physical and psychological changes can also have a substantial impact on the healthrelated quality of life (HRQoL) of both patients and their families [7, 8].

Recovering from ACS or related procedures, patients learn to adjust to these changes but also need to undertake many behaviours related to secondary prevention including managing their recovery, risk reduction and incorporation of key medications [9]. These behaviours are often referred to as selfmanagement and/or self-care, although the term self-management will be used in this paper. Self-management is commonly understood to involve a variety of activities which protect and promote health such as monitoring signs and symptoms, adhering to treatment, modifying lifestyle, and coping with the impact of disease on personal well-being and interpersonal relationships [10].

Self-management requires a person's capacity to act and make choices and is influenced by multiple factors including knowledge, culture, values, beliefs, language, social-economic status, motivation and self-efficacy $[11,12]$. The role of self-management in coronary heart disease recovery and particularly 
secondary prevention is important and can have a substantial impact on health outcomes. Appropriate self-management has been proven beneficial in reducing mortality and improving HRQoL $[13,14]$. Whereas poor selfmanagement can lead to a high recurrence, hospital re-admission and mortality, as well as poor HRQoL [15-17].

However, the complex nature of cardiac disease and variations in personal capacity mean that self-management can be challenging for patients. Selfmanagement following ACS or related procedures varies by ethnicity and migration status, and ethnic minorities and immigrant groups living in Western countries were found to be disadvantaged compared with the majority of local residents $[18,19]$. One example of an immigrant group present in many Western countries is people of Chinese ethnicity. This population is growing rapidly as China has become one of the largest migrant-exporting countries in the world; with more than 50 million ethnic Chinese emigrated in the past century $[20,21]$. In this paper, we refer to people of Chinese ethnicity as people born in or having ancestry from mainland China, Hong Kong, Macau, or Tai Wan, but living in a region apart from these areas. They can also be classified as first or second generation immigrants depending upon their own and their parents' birth regions $[22,23]$.

The prevalence of coronary heart disease increases in people of Chinese ethnicity living in Western countries such as Canada, the United Kingdom, and Australia, compared to those living in China [24, 25]. Furthermore, compared with the majority in host countries, health outcomes, especially the short-term mortality of coronary heart diseases, are worse in this group [26]. These epidemiologic changes are associated with lifestyle changes, stress, financial difficulties, as well as the duration of stay in Western countries [27]. 
These changes are also potentially due to difficulties in self-management of coronary heart disease for people of Chinese ethnicity which may include the access to and utilization of healthcare, interaction with health providers, and adherence to treatment[19, 28]. Such issues are complex and remain understudied and poorly understood. Therefore it is important to understand self-management and experiences in engaging with the healthcare system in people of Chinese ethnicity living in Western countries after ACS or related procedures, to identify the gap between their needs and what the healthcare system provides, to lay a foundation for developing tailored and culturally appropriate secondary prevention strategies.

\section{AIM}

The aim of this review is to explore self-management and experiences with the healthcare system after ACS or related procedures amongst people of Chinese ethnicity living in Western countries.

\section{METHODS}

\section{Design}

A scoping review was conducted using a systematic approach for the literature search. Scoping reviews were first described by Arksey \& O'Malley (2005) and updated by others in the past decade [29,30]. This is an explorative method, which addresses broad areas of evidence, explores breadth rather than depth, and generally does not require quality assessment, allowing the inclusion of both quantitative and qualitative studies as well as grey literature based on relevance to the topic [29]. This method is appropriate for areas that are understudied and complex and suitable for examining the available evidence and identifying gaps in the literature [31], which makes this method particularly relevant to the complex topic of selfmanagement. 


\section{Scoping review steps}

This scoping review followed the steps described by Levac et al (2010), namely (1) identifying the research question; (2) searching for relevant studies; (3) selecting studies; (4) charting data; (5) summarising, synthesising, and reporting results; as well as (6) validating the results with a multidisciplinary team including researchers and clinicians.

\section{Search strategies}

After identifying the research aim, a literature search using a systematic approach was conducted, which was limited to studies conducted in humans and reported in the English language before December 2015, using the bibliographic databases CINAHL, Medline (Ovid), Scopus, Embase, PsycINFO, and Proquest-Central. Both medical subject heading (Mesh) terms and keywords were used in searching (Table 1).

Duplicates were removed from the initially identified studies. We first assessed titles and abstracts and removed studies that were not relevant to the research question. The remaining studies were assessed in full text in detail and were checked by two independent reviewers ( $L Z, R G)$. Any new relevant papers identified in reference lists were then assessed. The studies not meeting inclusion criteria were removed (Figure 1).

\section{Inclusion criteria}

- Sample includes patients who have been admitted for ACS including unstable angina, as well as STEMI and non-STEMI, or related procedures such as coronary artery bypass graft (CABG), and percutaneous coronary intervention (PCl); 
- Studies conducted in people of Chinese ethnicity living in Western countries;

- Reported post-discharge self-management and self-care behaviours in above heart conditions and/or

- Reported experiences in access and utilisation of healthcare;

- Published in English.

\section{Charting, summarizing, and synthesizing data, reporting and validating} results

Data from each paper was charted, subsequently analysed and reported. Information regarding publication, study aim, study design, participants (age, gender), sample size, diagnosis, and main findings was extracted and summarised. After reviewing data and making notes, thematic analysis was used in analysing qualitative data.

An overview of the findings related to patients' self-management behaviours and experiences in accessing and utilisation of healthcare extracted from the studies was categorized into different domains, namely access and utilisation of healthcare, provider-patient interaction and self-care [12]. The first author (LZ) extracted the data, and a second author (RG) independently reviewed the extracted data. Potential disagreements were discussed to reaching consensus. Based on agreed data, patterns and themes were developed.

To validate the results in the last step, seven professionals were contacted to form a multidisciplinary panel, consisting of three senior cardiac nurses and four researchers. The three cardiac nurses, of whom two were Chinese, have extensive experience in caring for cardiac patients of Chinese ethnicity. Of the four researchers, two of whom were Chinese, one having expertise in health promotion, one in cross-cultural qualitative research, and two in cardiac 
disease secondary prevention. Uncertain findings were discussed between panel and authors until clarified.

\section{RESULTS}

This review included six studies that met the inclusion criteria (Table 2)[19, 28, 32-35]. Of the studies, four were qualitative and two were quantitative. These studies were conducted in Australia $(n=1)$, Canada $(n=3)$ and the United Kingdom ( $\mathrm{n=2}$ ). The sample sizes in the two quantitative studies were 258 and 436 participants and the sample sizes in the four qualitative studies were between 8 and 26 participants [19, 28, 32-35]. Most studies were focused on participants over the age of 65 years. The diagnoses included CHD, ACS, and AMI.

Four overarching themes were found, namely: 1) understanding of heart disease, risk factors and symptom recognition, 2) adherence to medication and lifestyle modification, 3) health service/information choice, and 4) family role in disease self-management and decision making. All themes were greatly influenced by language proficiency and cultural practices.

\section{Understanding of heart disease, risk factors, and symptom recognition}

The view of the heart and heart disease was explored in three studies [28, 32 , 35]. Chinese participants viewed the heart as a primary organ having physiological and psychological functions. While heart disease was viewed as an acute and serious condition [32, 35], it was viewed as less chronic than osteoarthritis and less serious than cancer [32].

Overall, Chinese participants did not fully understand the causes and risk factors of cardiac disease. The majority of participants in one study failed to identify important risk factors such as being male, over the age of 50 , and 
having diabetes [35]. Some participants in another study believed that heart disease was caused by family history or stress [28]. 34.9\% ( $n=152)$ of Chinese participants in the former study were not sure whether cardiac disease is curable [35].

Poor symptom recognition was reported in three studies [28, 32, 33]. No ethnic difference occurred between Chinese and non-Chinese in ACS symptom experience [33]. Although symptom recognition was poor in most participants of minority ethnicities [33], Chinese participants were more likely to ignore or deny the early symptoms of ACS, particularly when symptoms went away or were not intense [28, 32,33]. Some Chinese participants in one study also tended to link the early symptoms to musculoskeletal problems, rather than to the heart [33].

\section{Adherence to medication and lifestyle modification}

Adherence to medication or lifestyle modification was reported in four studies $[19,28,32,35]$. Chinese participants in one study were found to be less likely to adhere to overall medications, and had particularly poor adherence to ACE inhibitors compared with other ethnicities [19]. Medication adherence among Chinese participants in another study was found to be mainly based on their best interests as well as their symptom experiences [28].

Adherence to lifestyle modification was noted to be largely dependent on one's educational background, personal philosophy, beliefs, experiences, knowledge, and information shared with others [28, 32, 35]. Risk modification approaches often reflected participants' usual approach in decision making and philosophical foundation or faith. When a "straightforward approach" was used in daily life then a rapid dietary change was undertaken after the cardiac event. Whereas those who adopted a "peaceful accepting approach" in daily 
life then also accepted their diagnosis and information to help keep a peaceful mind and enhance their health [28].

When Western medicine recommendations were discordant with traditional beliefs, Chinese participants were less likely to follow the Western recommendations. For instance, attending cardiac rehabilitation (CR) became difficult as it was considered to be incongruent with traditional views of resting and relaxation during recovery [32]. Salt reduction became challenging, as many Chinese participants believed that a Chinese diet was healthier than a Western diet [28, 32, 35].

\section{Health service/information choice}

The majority of Chinese participants preferred to use bilingual health professionals and were hesitant to use emergency services in an urgent situation. Although Chinese participants respected Western practitioners, they still preferred to go to a Chinese or bilingual physician for interpreting health information, overcoming cultural barriers, and navigating the healthcare system [28, 32, 33]. A bilingual physician was described as "trusted" or "having better understanding" by Chinese participants $[28,33]$.

The underlying reasons for avoiding emergency services were language barriers, family responsibilities, and fear. Language barriers in accessing emergency services were reported in two studies $[28,33]$ and Chinese participants in one study tended to go to a Chinese physician and avoid seeking emergency services even in an emergency situation [33]. Using the emergency service was considered to be troublesome to their family for female Chinese participants in this study, they placed family responsibility above personal health needs[33]. Moreover, the fear of going to the hospital 
and not coming out of hospital again also caused hesitation in seeking emergency services in some Chinese participants from the same study [33].

Balancing between Western medicine and traditional Chinese medicine (TCM) is an important and common part of self-management in Chinese participants [28, 32, 34, 35]. The decision-making process was influenced by multiple factors such as beliefs and trust level in both medicines [28, 32, 34]. Use of TCM was found to be strongly linked with Chinese traditional beliefs, and it was considered as part of disease management and daily life [32]. Both medicines were used together or alternatively as both types of medicine were considered to have their own advantages[28, 34, 35]. Low level of trust in Western medicine led Chinese participants to seek help from TCM [34].

Although the majority of Chinese participants had high regard for authority and thus health professionals, evidenced by a quicker acceptance of their diagnosis, being diligent about attending appointments and eagerness to learn more information about their disease, in one study some participants were skeptical and selective of the health information provided [28].

\section{Family role in disease self-management and decision making}

The marital and familial relationship played a very important role in disease self-management and decision making as reported in two studies [28, 32]. The family role included supporting activities of daily life and assisting in navigating the healthcare system [28, 32]. Male participants tended to get help from their spouses, whereas female participants tended to get help from their children [28]. Moreover, family members had also involved in diseaserelated decision-making processes, although this was not described in detail [32]. 


\section{Validation by multidisciplinary panel}

The multidisciplinary panel independently reviewed the findings from the literature and provided feedback based on their clinical or research experience and their cultural understanding. The panel was in general agreement on the key findings in relation to aspects of self-management and experiences in engaging with the healthcare system in people of Chinese ethnicity. The panel confirmed the importance of the results in understanding Chinese immigrant patients in their care.

\section{DISCUSSION}

To our knowledge, this is the first review of self-management behaviours and experiences in engaging with the healthcare system in people of Chinese ethnicity living in Western countries who experienced a cardiac event or related procedures. The findings reveal some phenomenon relating to the utilisation of the healthcare system, interaction with a healthcare provider, and self-management. Overall Chinese culture was very influential to people of Chinese ethnicity who had ACS or related procedures, and language, beliefs and family values were identified as the most influential factors.

Firstly, limited English proficiency has often been reported as a barrier to selfmanagement, particularly to receiving health information and choosing healthcare [36-38]. Insufficient language capacity often hinders the interaction with healthcare providers. Patients of Chinese ethnicity are significantly less likely to receive or discuss the information about disease and prevention with healthcare professionals compared with other ethnicities. As a result lack of disease and healthcare services information is often observed in this population, particularly in older and recent immigrants [39, 40]. Consequently, when limited English proficiency combines with poor health knowledge, behaviours including non-healthcare seeking, self-diagnosis or self-treatment, delayed healthcare-seeking, and/or poor compliance to treatment are present 
[39, 40-45], which often lead to poor health outcomes [46].

These health behaviours may also reflect the low confidence level in utilizing healthcare services by people of Chinese ethnicity [40, 44, 47, 48. 49]. Healthcare seeking among these people is often considered as the last resort [40], and only occurs when the self-treatment fails or when the condition becomes worse, and often requires family members' assistance [44, 47-49]. This behaviour may also partially explain why ethnically and linguistically matched general practitioners are highly preferred by people of Chinese ethnicity regardless of the severity of the medical condition [39, 50, 51]. However, such a specific preference may lead to delays in receiving appropriate treatment, and consequentially worse health outcomes [52].

Secondly, certain Chinese traditional health beliefs have shown to be influential on perceptions of illness/health and TCM/Western medicine amongst people of Chinese ethnicity, further impacting on their choice of type of medicine [53-56]. Beliefs held by this population are often incorporated into disease management, as well as daily life. The cardiac condition is believed as acute rather than chronic in this population. Based on this belief, poor medication adherence is not surprising $[53,55]$.

Furthermore, the beliefs of Western medicine and TCM held by this population often influence their choice of type of medicines as TCM is often viewed as a cultural heritage and is believed to have fewer side-effects and to treat health problems in a holistic way, which is in contrast to views of Western medicine $[54,56]$. In this population, TCM is used as an important resource in many disease's management, as well as in self-treating minor illnesses [56, 57]. A high rate of using TCM is also found in those holding a view that Western medicine cannot completely cure a chronic disease $[45,50]$, and acculturation 
and success experiences with Western medicine do not necessarily discontinue in using TCM in this population [50]. Despite the high rate of using TCM, patients of Chinese ethnicity were rarely informed or assessed regarding their use of TCM by Western medicine practitioners, which might lead to drug interaction or even worse consequences [58].

Finally, the family is a core part of the Chinese value system and it plays an essential role in disease management. This needs to be considered in light of the Chinese value system. Family members are identified as a primary source of social support, playing an important role in supporting disease management and decision-making [40]. Given the role of the family as a central unit in Chinese culture, it is not surprising that family members act as caregivers, providing support and facilitate disease management, as well as making a decision regarding medical treatment $[40,53,59,60]$. Compare to male, female family members are more likely to take the caregiver role and they are more likely to view the family responsibility beyond their own health needs. Such a view may prevent them from seeking healthcare and silence the suffering $[54,60,61]$.

\section{LIMITATION}

The limitation of this scoping review is that the included studies do not always describe the post cardiac event experiences explicitly, extensively, or clearly. Therefore bias may have been introduced by the interpretation of reviewers. However, a multidisciplinary team was referred to validate the results in an effort to minimize possible bias.

\section{CONCLUSION}

The findings from this review show there are ethnic disparities in selfmanagement and utilisation of health information and resources amongst 
people of Chinese ethnicity living in Western countries. These disparities are influenced by English language proficiency and Chinese culture/beliefs, which are deeply embedded in every aspect of disease self-management.

Developing culturally appropriate and sensitive interventions in the Chinese language is needed to improve cardiac disease self-management in this population. 


\section{ACKNOWLEDGEMENT}

The authors have no financial relationships relevant to this article to disclose. 


\section{References:}

1. Smith SC, Jr, Collins A, Ferrari R, Holmes DR, Jr, Logstrup S, McGhie DV,...Zoghbi WA: Our time: a call to save preventable death from cardiovascular disease (heart disease and stroke). Glob Heart 2012; 7(4):297-305.

2. Alsen P, Brink E, Brandstrom Y, Karlson BW, Persson LO: Fatigue after myocardial infarction: relationships with indices of emotional distress, and sociodemographic and clinical variables. Int J Nurs Pract 2010; 16(4): 326-34.

3. Fredriksson-Larsson U, Alsen P, Karlson BW, Brink, E: Fatigue two months after myocardial infarction and its relationships with other concurrent symptoms, sleep quality and coping strategies. J Clin Nurs 2015; 24(15-16): 2192-200.

4. Dixon T, Lim LL, Powell H, Fisher JD: Psychosocial experiences of cardiac patients in early recovery: a community-based study. J Adv Nurs 2000; 31(6): 1368-75.

5. Benyamini Y, Roziner I, Goldbourt U, Drory Y, Gerber Y: Depression and anxiety following myocardial infarction and their inverse associations with future health behaviors and quality of life. Ann Behav Med 2013; 46(3): 310-21.

6. Christman NJ, McConnell EA, Pfeiffer C, Webster KK, Schmitt M, Ries J: Uncertainty, coping, and distress following myocardial infarction: transition from hospital to home. Res Nurs Health 1988; 11(2): 71-82.

7. Chan DS, Chau JP, Chang AM: Quality of life of Hong Kong Chinese diagnosed with acute coronary syndromes. J Clin Nurs 2005; 14(10): 1262-3.

8. Bergman E, Malm D, Karlsson JE, Bertero C: Longitudinal study of patients after myocardial infarction: sense of coherence, quality of life, and symptoms. Heart Lung 2009; 38(2): 129-40.

9. Lorig K, Holman H, Sobel D, Gonzalez V, Minor M: Overview of sefl-management, in Living a healthy life with chronic conditions: self-management of heart disease, arthritis, diabetes, asthma, bronchitis, emphysema and others. Boulder: Bull publishing company; 2006:12-14.

10. Clark NM, Becker MH, Janz NK, Lorig K, Rakowski W, Anderson L: Self-management of chronic disease by older adults. A review and questions for research. Journal of Aging and Health 1991; 3(1): 3-27.

11. Gantz SB: Self-care: perspectives from six disciplines. Holist Nurs Pract 1990; 4(2): 1-12.

12. Paasche-Orlow MK, Wolf MS, The causal pathways linking health literacy to health outcomes. Am J Health Behav 2007; 31 Suppl 1: S19-26.

13. Wang W, Jiang Y, He HG, Koh KW: A randomised controlled trial on the effectiveness of a homebased self-management programme for community-dwelling patients with myocardial infarction. Eur J Cardiovasc Nurs 2015; doi:10.1177/1474515115586904.

14. Niakan M, Paryad E, Kazemnezhad Leili E, Sheikholeslami F: Depressive symptoms effect on self care behavior during the first month after myocardial infarction. Glob J Health Sci 2015; 7(4): 382-91.

15. Mathews R, Peterson ED, Honeycutt E, Chin CT, Effron MB, Zettler M....Wang TY: Early Medication Nonadherence After Acute Myocardial Infarction: Insights into Actionable Opportunities From the TReatment with ADP receptor iNhibitorS: Longitudinal Assessment of Treatment Patterns and Events after Acute Coronary Syndrome (TRANSLATE-ACS) Study. Circ Cardiovasc Qual Outcomes 2015; 8(4): 347-56.

16. Lauffenburger JC, Robinson JG, Oramasionwu C, Fang G: Racial/Ethnic and gender gaps in the use of and adherence to evidence-based preventive therapies among elderly Medicare Part $D$ 
beneficiaries after acute myocardial infarction. Circulation 2014; 129(7): 754-63.

17. Gazmararian JA, Kripalani S, Miller MJ, Echt KV, Ren J, Rask K: Factors associated with medication refill adherence in cardiovascular-related diseases: a focus on health literacy. J Gen Intern Med 2006; 21(12): 1215-21.

18. Zullig LL, Shaw RJ, Shah BR, Peterson ED, Lindquist JH, Crowley MJ....Bosworth HB: Patientprovider communication, self-reported medication adherence, and race in a postmyocardial infarction population. Patient Prefer Adherence 2015; 9: 311-8.

19. Lai EJ, Grubisic M, Palepu A, Quan H, King KM, Khan NA: Cardiac medication prescribing and adherence after acute myocardial infarction in Chinese and South Asian Canadian patients. BMC Cardiovasc Disord 2011; 11: 56.

20. Hoeffel EM, Rastogi S, Kim MO: The Asian population (2010), E.a.S.A. US Department of Commerce, Editor. 2010, US Census Bureau.

21. Gryn T, Gambino C: The foreign born of Asia: 2011, A.C.S. Briefs, Editor. 2012.

22. Guo S, DeVoretz DJ: The changing face of Chinese immigrants in Candada. Journal of International Migration and Intergration 2006; 7(3): 275-300.

23. Algan Y, Dustmen C, Glitz A, Manning A: The ecnomic situation in first and second-generation immigrants in France, Germany, and the United Kindom. The Economic Journal 2010; 120 (542): F4-F30.

24. Chiu JF, Bell AD, Herman RJ, Hill MD, Stewart JA, Cohen EA.....Bhatt DL: Cardiovascular risk profiles and outcomes of Chinese living inside and outside China. Eur J Cardiovasc Prev Rehabil 2010; 17(6): 668-75.

25. Gong Z, Zhao D: Cardiovascular diseases and risk factors among Chinese immigrants. Intern Emerg Med; 2015. doi:10.1007/s11739-015-1305-6

26. Jin K, Ding D, Gullick J, Koo F, Neubeck L: A Chinese Immigrant Paradox? Low Coronary Heart Disease Incidence but Higher Short-Term Mortality in Western-Dwelling Chinese Immigrants: A Systematic Review and Meta-Analysis. J Am Heart Assoc 2015; 4(12). Doi:10.1161/jaha.115.002568.

27. Tu JV, Chu A, Rezai MR, Guo H, Maclagan LC, Austin PC......Alter DA: The Incidence of Major Cardiovascular Events in Immigrants to Ontario, Canada: The CANHEART Immigrant Study. Circulation 2015; doi:10.1161/circulationaha.115.015345

28. King KM, LeBlanc $\mathrm{P}$, Carr W, Quan H: Chinese immigrants' management of their cardiovascular disease risk. West J Nurs Res 2007; 29(7): 804-26.

29. Levac D, Colquhoun H, O'Brien KK, Scoping studies: advancing the methodology. Implement Sci 2010; 5: 69 .

30. Daudt HM, van Mossel C, Scott SJ: Enhancing the scoping study methodology: a large, interprofessional team's experience with Arksey and O'Malley's framework. BMC Med Res Methodol 2013; 13: 48.

31. Arksey H, O'Malley L: Scoping studies: towards a methodological framework. International Journal of Social Research Methodology 2005; 8(1): 19-32.

32. Davidson PM, Daly J, Leung D, Ang E, Paull G, DiGiacomo M.....Thompson DR: Health-seeking beliefs of cardiovascular patients: a qualitative study. Int I Nurs Stud 2011; 48(11): 1367-75.

33. King-Shier KM, Singh $\mathrm{S}$, LeBlanc $\mathrm{P}$, Mather $\mathrm{CM}$, Humphrey $\mathrm{R}$, Quan $\mathrm{H}$, Khan NA: The influence of ethnicity and gender on navigating an acute coronary syndrome event. Eur J Cardiovasc Nurs 2015; 14(3): 240-7. 
34. Liu Z, Speed S: Where east fails to meet west: The consequences for Chinese elders in the north west of England who seek help for cardio-vascular disease. Journal of Alternative and Complementary Medicine 2014; 20(5).

35. Za T, Lau JCF, Wong ACK, Wong AWS, Lui S, Fong JWD....Jolly KB: Perceptions of risk factors of cardiovascular disease and cardiac rehabilitation: A cross-sectional study targeting the Chinese population in the Midlands, UK. Heart Asia 2014; 4(1): 57-61.

36. Grunau GL, Ratner PA, Galdas PM, Hossain S: Ethnic and gender differences in patient education about heart disease risk and prevention. Patient Educ Couns 2009; 76(2): 181-8.

37. Karliner LS, Auerbach A, Napoles A, Schillinger D, Nickleach D, Perez-Stable EJ: Language barriers and understanding of hospital discharge instructions. Med Care 2012 50(4): 283-9.

38. Green AR, Ngo-Metzger Q, Legedza AT, Massagli MP, Phillips RS, Lezzoni LI: Interpreter services, language concordance, and health care quality. Experiences of Asian Americans with limited English proficiency. J Gen Intern Med 2005; 20(11): 1050-6.

39. Wang L, Rosenberg M, Lo L: Ethnicity and utilization of family physicians: a case study of Mainland Chinese immigrants in Toronto, Canada. Social Science \& Medicine 2008; 67(9): 1410-1422.

40. Pang EC, Jordan-Marsh M, Silverstein M, Cody M: Health-seeking behaviors of elderly Chinese Americans: shifts in expectations. Gerontologist 2003; 43(6): 864-74.

41. Liu Z, Speed S, Beaver K: Perceptions and attitudes towards exercise among Chinese elders the implications of culturally based self-management strategies for effective health-related help seeking and person-centred care. Health Expect 2015; 18(2): 262-72.

42. Marshall EG, Wong ST, Haggerty JL, Levesque JF: Perceptions of unmet healthcare needs: what do Punjabi and Chinese-speaking immigrants think? A qualitative study. BMC Health Serv Res 2010; 10: 46

43. Washington G, Wang-Letzkus MF: Self-care practices, health beliefs, and attitudes of older diabetic Chinese Americans. J Health Hum Serv Adm 2009; 32(3): 305-23.

44. Ma GX: Barriers to the use of health services by Chinese Americans. J Allied Health 2000; 29(2): 64-70.

45. Zhang J, Verhoef MJ: Illness management strategies among Chinese immigrants living with arthritis. Social Science \& Medicine 2002; 55(10): 1795-1802.

46. Sentell T, Braun KL: Low health literacy, limited English proficiency, and health status in Asians, Latinos, and other racial/ethnic groups in California. J Health Commun 2012; 17 Suppl 3: 8299.

47. Leung AY, Bo A, Hsiao HY, Wang SS, Chi I: Health literacy issues in the care of Chinese American immigrants with diabetes: a qualitative study. BMJ Open 2014: 4(11): e005294.

48. Gulati S, Watt L, Shaw N, Sung L, Poureslami IM, Klaassen R.....Klassen AF: Communication and language challenges experienced by Chinese and South Asian immigrant parents of children with cancer in Canada: implications for health services delivery. Pediatr Blood Cancer 2012; 58(4): 572-8.

49. Arora A, Liu MN, Chan R, Schwarz E: 'English leaflets are not meant for me': a qualitative approach to explore oral health literacy in Chinese mothers in Southwestern Sydney, Australia. Community Dent Oral Epidemiol 2012; 40(6): 532-41.

50. Green G, Bradby H, Chan A, Lee M: "We are not completely Westernised": dual medical systems and pathways to health care among Chinese migrant women in England. Social Science \& 
Medicine 2006; 62(6): 1498-1509.

51. Todd L, Hoffman-Goetz L: A qualitative study of cancer information seeking among English-asa-second-Language older Chinese immigrant women to Canada: sources, barriers, and strategies. J Cancer Educ 2011; 26(2): 333-40.

52. King KM, Khan NA, Quan H: Ethnic variation in acute myocardial infarction presentation and access to care. Am J Cardiol 2009; 103(10): 1368-73.

53. Jin L, Acharya L: Cultural Beliefs Underlying Medication Adherence in People of Chinese Descent in the United States. Health Communication 2015; 1-9.

54. Kong $\mathrm{H}, \mathrm{Hsieh} \mathrm{E}$ : The social meanings of traditional Chinese medicine: elderly Chinese immigrants' health practice in the United States. Journal of Immigrant and Minority Health 2012; 14(5): 841-849.

55. Li WW, Stewart AL, Stotts N, Froelicher ES: Cultural factors associated with antihypertensive medication adherence in Chinese immigrants. J Cardiovasc Nurs 2006; 21(5): 354-62.

56. Wu AP, Burke A, LeBaron S: Use of traditional medicine by immigrant Chinese patients. Fam Med 2007; 39(3): 195-200.

57. Ma GX: Between two worlds: the use of traditional and Western health services by Chinese immigrants. J Community Health 1999; 24(6): 421-37.

58. Leng JC, Gany F: Traditional Chinese medicine use among Chinese immigrant cancer patients. J Cancer Educ 2014; 29(1): 56-61.

59. Kwok C, White K: Perceived information needs and social support of Chinese-Australian breast cancer survivors. Support Care Cancer 2014; 22(10): 2651-9.

60. Liu LW, McDaniel SA: Family Caregiving for Immigrant Seniors Living With Heart Disease and Stroke: Chinese Canadian Perspective. Health Care Women Int 2015; 36(12): 1327-45.

61. Wong ST, Yoo GJ, Stewart AL: Examining the types of social support and the actual sources of support in older Chinese and Korean immigrants. Int J Aging Hum Dev 2005; 61(2): 105-21. 


\section{Table 1 . Search string of scoping review.}

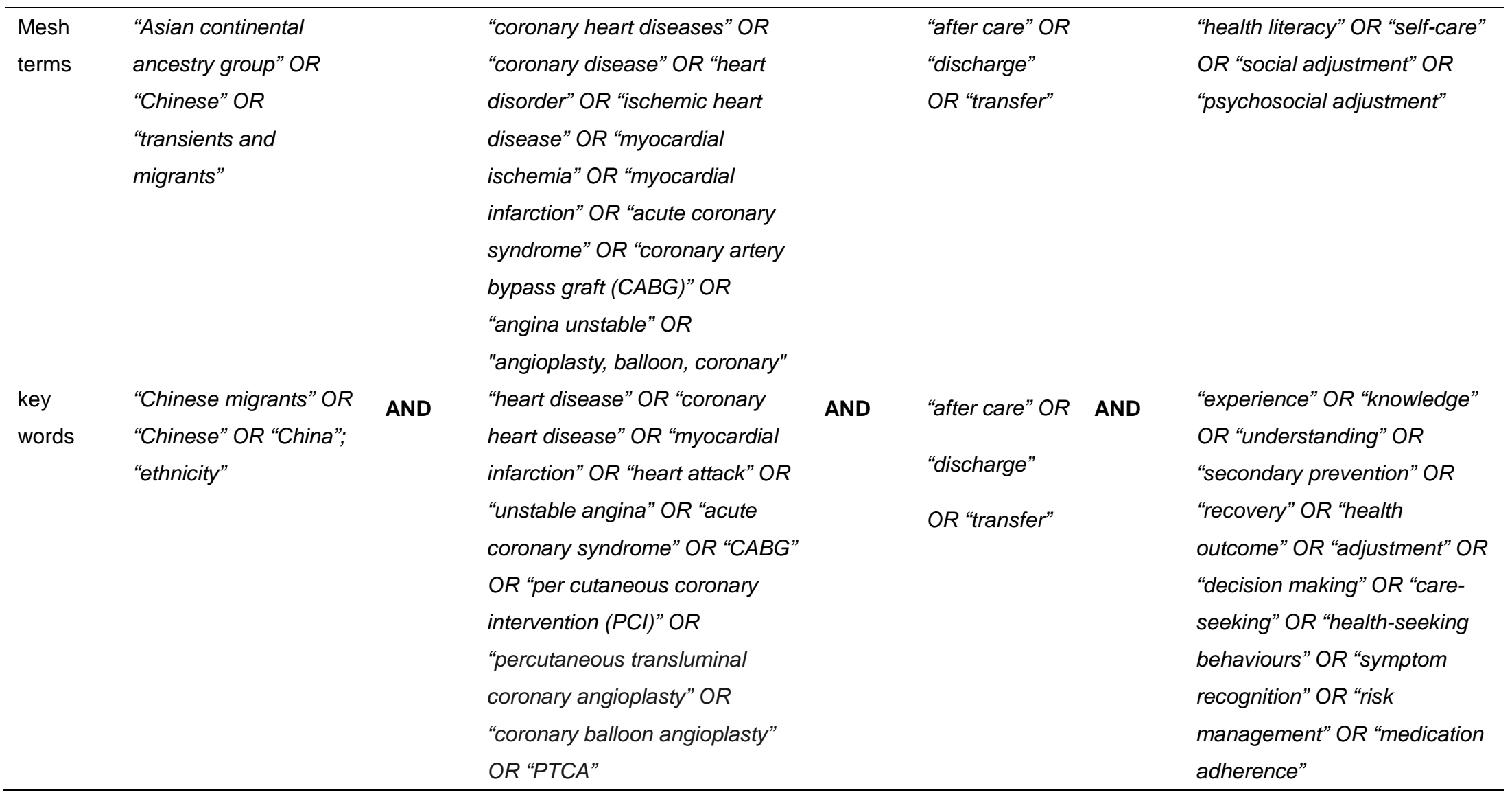


Table 2 . Study description and main finding.

\begin{tabular}{|c|c|c|c|c|}
\hline $\begin{array}{l}\text { References } \\
\text { Country }\end{array}$ & Study Design & Sample Description & Focus & Main findings \\
\hline $\begin{array}{l}32] \\
\text { Australia }\end{array}$ & $\begin{array}{l}\text { Qualitative } \\
\text { study using } \\
\text { thematic } \\
\text { analysis }\end{array}$ & $\begin{array}{l}\text { All Chinese: } \mathrm{n}=78 \text { focus } \\
\text { group ( } 68 \text { years mean } \\
\text { age), } \mathrm{n}=8 \text { individual } \\
\text { interview ( } 74 \text { years } \\
\text { mean age); } \mathrm{n}=13 \text { health } \\
\text { professional ( } 44 \text { years } \\
\text { mean age) }\end{array}$ & $\begin{array}{l}\text { Post cardiac event } \\
\text { experiences }\end{array}$ & $\begin{array}{l}\text { - Traditional Chinese view is heart is primary organ so heart } \\
\text { disease is a serious condition, but not as serious as cancer or as } \\
\text { chronic as osteoarthritis; traditional Chinese medicine (TCM) } \\
\text { helps to restore inner balance, recovery and bring sense of } \\
\text { coherence. } \\
\text { - Traditional beliefs were followed in preference to Western } \\
\text { medicine recommendations, so dietary modification and cardiac } \\
\text { rehabilitation became challenging. } \\
\text { Medical practitioners were respected but, bilingual practitioners } \\
\text { were valued and preferred as mediators between cultures and } \\
\text { treatment modalities. } \\
\text { Family is important for support and brokering healthcare system } \\
\text { and relied upon for decision-making. }\end{array}$ \\
\hline $\begin{array}{l}{[28]} \\
\text { Canada }\end{array}$ & $\begin{array}{l}\text { Qualitative } \\
\text { study using } \\
\text { grounded } \\
\text { theory }\end{array}$ & $\begin{array}{l}15 \text { Chinese participants } \\
\text { (age range } 53-83 \text { years) }\end{array}$ & $\begin{array}{l}\text { Influence of Chinese } \\
\text { ethnocultural beliefs on } \\
\text { behaviour change post } \\
\text { cardiac event }\end{array}$ & $\begin{array}{l}\text { - Some CVD risk factors were identified but lack of understanding } \\
\text { of causes of cardiac disease, and belief family history or stress } \\
\text { was main cause. } \\
\text { - Rapid acceptance of diagnosis and behavior change phase. Risk } \\
\text { factor modification usually initiated by cardiac diagnosis or event. } \\
\text { - Approach to risk reduction based on individual's education, } \\
\text { personal philosophy, beliefs, experiences, knowledge and shared } \\
\text { information. }\end{array}$ \\
\hline
\end{tabular}




\begin{tabular}{|c|c|c|c|c|}
\hline & & & & $\begin{array}{l}\text { - Self-management based on personal beliefs for adjusting } \\
\text { medication, seeking best health care and resources, being } \\
\text { selective and skeptical regarding health information and medicine } \\
\text { choices. } \\
\text { - Great respect for health professionals and diligence in attending } \\
\text { appointments and CR. } \\
\text { - Marital and familial relationship important in managing CVD risk. } \\
\text { - Language barriers posed problems and were overcome by family. }\end{array}$ \\
\hline $\begin{array}{l}\text { [33] } \\
\text { Canada }\end{array}$ & $\begin{array}{l}\text { Qualitative } \\
\text { study using } \\
\text { grounded } \\
\text { theory }\end{array}$ & $\begin{array}{l}20 \text { Caucasian } \\
18 \text { Chinese } \\
19 \text { South Asian } \\
\text { (65+years) }\end{array}$ & $\begin{array}{l}\text { Recognition of } \\
\text { symptoms, decision- } \\
\text { making, and healthcare } \\
\text { seeking }\end{array}$ & $\begin{array}{l}\text { All ethnicities had similar process of having symptoms; } \\
\text { waiting/denying; justifying; disclosing/discovery; acquiescing; } \\
\text { taking action. Care-seeking occurred only when symptoms } \\
\text { persistent, intense and pre-exposure to ACS. } \\
\text { - Chinese participants, particular females, tended to delay care- } \\
\text { seeking and avoid seeking urgent care based on beliefs, family } \\
\text { responsibilities or due to misinterpretation of ACS symptoms. } \\
\text { - Chinese participants often had language barriers and relied on } \\
\text { "trusted" physicians from their linguistic and cultural background } \\
\text { to help navigate healthcare systems. }\end{array}$ \\
\hline $\begin{array}{l}\text { [19] } \\
\text { Canada }\end{array}$ & $\begin{array}{l}\text { Retrospective } \\
\text { cohort study }\end{array}$ & $\begin{array}{l}9926 \text { acute myocardial } \\
\text { infarction (AMI) survivor } \\
\text { (65+ years,258 Chinese, } \\
511 \text { South Asian, and } \\
9157 \text { Non-Asian) }\end{array}$ & Medication adherence & $\begin{array}{l}\text { Chinese and South Asian participants prescribed more } \\
\text { medications in three months post-discharge compared to non- } \\
\text { Asian. Chinese participants more likely to be prescribed beta } \\
\text { blockers. } \\
\text { Chinese participants less likely to be adherent to overall } \\
\text { medication (OR: } 0.70 ; 95 \% \mathrm{Cl} ; 0.51-0.95 \text { ), and ACE inhibitors } \\
\text { compared with non-Asian (OR: } 0.53 ; 95 \% \mathrm{Cl} ; 0.39-0.73 \text { ). }\end{array}$ \\
\hline [34] & Qualitative & 26 Chinese (age was not & Utilisation of health & - Variable level of trust in Western Medicine \\
\hline
\end{tabular}




\begin{tabular}{|l|l|l|l|l|}
\hline $\begin{array}{l}\text { United } \\
\text { Kingdom }\end{array}$ & $\begin{array}{l}\text { study using } \\
\text { grounded } \\
\text { theory }\end{array}$ & $\begin{array}{l}\text { reported) } \\
7 \text { health professionals }\end{array}$ & services & $\begin{array}{l}\text { Both Western and TCM were used intermittently. Discontent with } \\
\text { treatment in one resulted in seeking the other. }\end{array}$ \\
\hline $\begin{array}{l}\text { United } \\
\text { Kingdom }\end{array}$ & Cross-sectional & 436 Chinese (18+ years) & $\begin{array}{l}\text { CVD knowledge and CR } \\
\text { awareness }\end{array}$ & $\begin{array}{l}\text { The majority identified risk factors such as obesity (80.7\%), but } \\
\text { not older age (64.7\%), diabetes (68.6\%), and being male (87.4\%); } \\
34.9 \% \text { did not know whether cardiac disease is curable. }\end{array}$ \\
& & & $\begin{array}{l}30 \% \text { heard of CR and were optimistic about it. } \\
\text { 81.7\% used Western medicine more than TCM. } 47.7 \% \text { and } 44 \% \\
\text { perceived Western medicine or a mixture of both medicines } \\
\text { more effective than TCM alone. }\end{array}$ \\
& & & $\begin{array}{l}56.2 \% \text { of participants aged }>50 \text { saw Western medicine as the best } \\
\text { treatment, younger participants saw a mixture of both medicines } \\
\text { as better. }\end{array}$ \\
\hline
\end{tabular}

Legend: TCM traditional Chinese medicine, CR Cardiac rehabilitation 


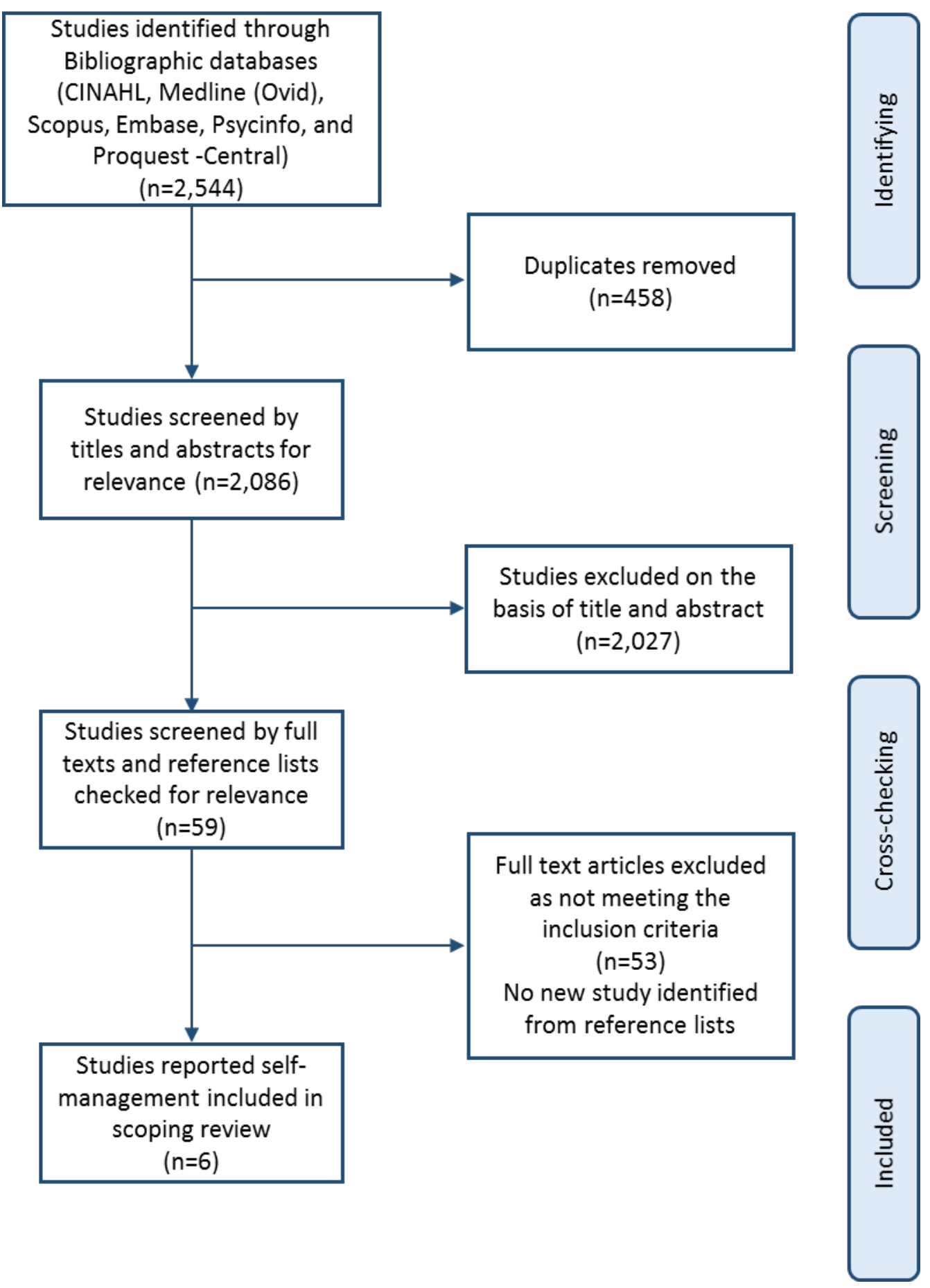

Figure 1. Literature search flow diagram 